\title{
Percutaneous aortic balloon dilatation for calcific aortic stenosis in elderly patients: immediate haemodynamic results and short term follow up
}

\author{
CARLO DI MARIO, $†$ KEVIN J BEATT, PIM DE FEYTER, \\ MARCEL VAN DEN BRAND, CATHARINA E ESSED, * PATRICK W SERRUYS
}

From the Thoraxcenter, Erasmus University, and the ${ }^{\star}$ First Department of Pathology, University Hospital Dijkzigt, Rotterdam, The Netherlands

SUMMARY Eight elderly patients (mean (SD) age $72 \cdot 6(8 \cdot 5)$ years) with severe calcified stenosis of the aortic valve were considered for transluminal balloon dilatation in the Thoraxcenter between March and November 1986. In one patient the procedure could not be performed because of technical difficulties. Balloons of increasing diameter (13-25 $\mathrm{mm}$ ) were successively passed retrogradely from the femoral artery and manually inflated with pressures of $400-600 \mathrm{kPa}$ (4-6 atmospheres). Post-dilatation, there were significant changes in left ventricular pressures (from 237/21 to $204 / 13 \mathrm{~mm} \mathrm{Hg}$ ), mean systolic gradient (from 66 to $41 \mathrm{~mm} \mathrm{Hg}$, systolic aortic flow (from 172 to $202 \mathrm{ml} / \mathrm{s}$, and aortic valve area (from 0.47 to $0.74 \mathrm{~cm}^{2}$ ); the cardiac index did not increase significantly (from 2.4 to $2.51 / \mathrm{min} / \mathrm{m}^{2}$ ). One patient developed a pseudoaneurysm at the site of the femoral artery puncture that required surgical repair two months after the procedure; one patient experienced an acute left hemianopia during the procedure but had almost completely recovered at discharge. Five patients maintained a clinical improvement at a mean follow up time of 4.5 months after the procedure; two patients underwent aortic valve replacement, one because of minimal haemodynamic improvement after aortic balloon dilatation and persistence of severe dyspnoea and the other because of late recurrence of symptoms caused by restenosis after a successful procedure.

Aortic balloon dilatation provides an alternative treatment for patients who are poor surgical candidates for cardiac or extracardiac reasons. At this stage the limited haemodynamic improvements suggest that the treatment can only be regarded as palliative, although proposed technical advances may achieve better immediate results in the future. Long term follow up is needed to evaluate the usefulness of this technique.

The poor prognosis of adult patients with symptomatic aortic stenosis has been known for some time: in particular Ross and Braunwald and Frank et al showed that patients who develop left ventricular failure have a high yearly mortality. ${ }^{12}$ An increasing number of studies have reported that aortic valve replacement can be performed with a reasonable operative mortality and encouraging long term survival, even in patients who are $>70$ years old. ${ }^{3-5}$

Requests for reprints to Dr Patrick W Serruys, Catheterization Laboratory, Thoraxcenter, PO Box 1738, 3000 DR Rotterdam, The Netherlands.

†Present address: Divisione Cardiologica, Cittadella (PD), Italy. Accepted for publication 13 May 1987
Although improvements in surgical techniques and postoperative care have lowered the operative mortality rate, associated diseases often make the management of many elderly patients difficult and this has encouraged the development of alternative methods of treatment.

We report the technique and the immediate results and complications of percutaneous aortic balloon dilatation in seven consecutive elderly patients with acquired calcific aortic stenosis.

\section{Patients and methods}

CLINICAL DATA

Since March 1986 eight patients (mean (SD) age 74 (8.8), range $63-84 ; 4$ men and 4 women) have been 
considered for percutaneous aortic balloon dilatation. The procedure was performed in only seven patients because one, patient 4 , a 84 year old man with severe aortic stenosis, was excluded because he had tortuous iliac and subclavian vessels that made diagnostic haemodynamic evaluation difficult. Table 1 shows the clinical data. Two patients were in functional class II of the New York Heart Association and six were in class III. Five patients had a history of previous angina and three of syncopal attacks. Two patients (cases 6 and 7) had signs of congestive heart failure. Most patients presented with associated cardiovascular (cases 3, 5, 6) or non-cardiovascular diseases (cases 4,7 ) or both (case 1).

Patient 6 had previously undergone a mitral valve replacement for severe mixed mitral valve disease. A recent catheterisation had confirmed a well functioning Björk-Shiley prosthesis in the mitral position with severe aortic stenosis (valve area $=0.5 \mathrm{~cm}^{2}$ ), and mild pulmonary hypertension (arteriolar pulmonary resistance 262 dyn $\mathrm{s} \mathrm{cm}^{-5}$ ). Two patients (cases 2 and 8) had previously declined aortic valve replacement, and were referred to our centre specifically for percutaneous aortic balloon dilatation. Neither had concomitant disease. Percutaneous aortic balloon dilatation was felt to be justified in all patients because of the relatively high surgical risk associated with advanced age, poor general health, and concomitant diseases.

HAEMODYNAMIC AND ANGIOGRAPHIC DATA Left ventricular and aortic pressures and mean systolic transaortic gradients were averaged and calculated on line after acquisition periods of 20 seconds. Cardiac output was computed from duplicate thermodilution measurements by a computerised system that also enabled instant calculation of systolic aortic flow and aortic valve area. ${ }^{6}$ Table 2 shows the basal haemodynamic data. All patients had a mean systolic gradient $>40$ $\mathrm{mm} \mathrm{Hg}$ (in three it was $>70 \mathrm{~mm} \mathrm{Hg}$ ) and an aortic valve area $\leqslant 0.7 \mathrm{~cm}^{2}$.
Large, localised areas of aortic valve calcification were detected in all the patients. Mean (SD) left ventricular end diastolic and end systolic volumes, normalised for body surface area, were $81(10) \mathrm{ml} / \mathrm{m}^{2}$ and $41(17) \mathrm{ml} / \mathrm{m}^{2}$ respectively, left ventricular ejection fraction ranged from 30 to $65 \%$ (mean $51 \%$ ), and left ventricular weight ranged from 136 to 209 $\mathrm{g} / \mathrm{m}^{2}$ (mean $164 \mathrm{~g} / \mathrm{m}^{2}$ ).

A trace of aortic insufficiency was present in three patients, and there was mild aortic regurgitation in three others. A competent aortic valve was found in one patient.

The aetiology of the aortic valve stenosis was rheumatic in case 6; a presumed degenerative pathogenesis was suspected in the other patients who were $\geqslant 63$ years old and who had late discovery of a cardiac murmur with no previous history of acute rheumatic fever.

\section{BALLOON DILATATION PROCEDURE}

After being informed of the possible risks of the procedure all patients gave their informed consent. Percutaneous aortic balloon dilatation was performed in two patients at the time of the diagnostic catheterisation and at a separate session in five patients. A Swan-Ganz thermodilution catheter was positioned in the pulmonary artery via the left femoral vein and a $7 F$ pigtail catheter was placed via the left femoral artery in the ascending aorta.

Before we started percutaneous aortic balloon dilatation, we gave intravenous atropine $(1.0 \mathrm{mg})$ and heparin (5000 IU). One to two units of blood were usually infused to expand the circulating volume. We found that these patients were susceptible to severe hypotension caused by the loss of small amounts of blood associated with the exchange of catheters.

We advanced a left 7F Judkins or Amplatz catheter through the right femoral artery into the ascending aorta just above the aortic cusps and directed its tip towards the jet stream. Thereafter, a straight 0.038 inch guide wire was used to cross the aortic valve. After the basal left ventricular pressures

Table 1 Clinical data

\begin{tabular}{|c|c|c|c|c|c|c|}
\hline Patient & Age & Sex & $N Y H A$ & Angina & Syncope & Associated diseases \\
\hline 1 & 76 & $\mathbf{M}$ & III & + & + & $\begin{array}{l}\text { Diabetes mellitus, nephrolithiasis two-vessel } \\
\text { CAD }\end{array}$ \\
\hline $\begin{array}{l}2 \\
3 \\
4 \\
5 \\
6 \\
7 \\
8\end{array}$ & $\begin{array}{l}63 \\
64 \\
84 \\
82 \\
65 \\
83 \\
75\end{array}$ & $\begin{array}{l}\text { M } \\
\mathbf{F} \\
\mathbf{M} \\
\mathbf{F} \\
\mathbf{F} \\
\mathbf{F} \\
\mathbf{M}\end{array}$ & $\begin{array}{l}\text { II } \\
\text { II } \\
\text { III } \\
\text { III } \\
\text { III } \\
\text { III } \\
\text { III }\end{array}$ & $\begin{array}{l}+ \\
+ \\
+ \\
+ \\
+\end{array}$ & $\begin{array}{l}- \\
\overline{+} \\
- \\
- \\
+\end{array}$ & $\begin{array}{l}\text { None } \\
\text { Systemic hypertension, arterial claudication } \\
\text { Chronic obstructive lung disease } \\
\text { Three vessel CAD } \\
\text { Mitral prosthesis } \\
\text { Anaemia, rheumatoid arthritis } \\
\text { None }\end{array}$ \\
\hline
\end{tabular}

CAD, coronary artery disease; NYHA, New York Heart Association class. 
Table 2 Haemodynamic data before and after aortic valve dilatation in 7 elderly patients

\begin{tabular}{|c|c|c|c|c|c|c|c|c|c|c|c|c|}
\hline \multirow[t]{2}{*}{ Patient } & \multicolumn{2}{|l|}{$L V$} & \multicolumn{2}{|l|}{ Aorta } & \multicolumn{2}{|l|}{$M S G$} & \multicolumn{2}{|l|}{$C I$} & \multicolumn{2}{|l|}{$A F$} & \multicolumn{2}{|l|}{$A A$} \\
\hline & Before & After & Before & After & Before & After & Before & After & Before & After & Before & Afte\& \\
\hline $\begin{array}{l}1 \\
2 \\
3 \\
4 \\
5 \\
6 \\
7 \\
\text { Mean (SD) }\end{array}$ & $\begin{array}{l}247 / 24 \\
275 / 31 \\
264 / 15 \\
230 / 16 \\
204 / 23 \\
238 / 12 \\
203 / 28 \\
237 / 21 \quad(28 / 7) \\
\quad p<\end{array}$ & $\begin{array}{l}229 / 11 \\
222 / 16 \\
177 / 2 \\
188 / 19 \\
210 / 23 \\
212 / 2 \\
188 / 15 \\
204 / 13(19 / 8) \\
0.05\end{array}$ & $\begin{array}{l}191 / 77 \\
177 / 86 \\
198 / 81 \\
157 / 63 \\
150 / 67 \\
133 / 57 \\
156 / 90 \\
166 / 74(23 / 9)\end{array}$ & $\begin{array}{l}201 / 84 \\
154 / 66 \\
142 / 73 \\
166 / 63 \\
174 / 83 \\
142 / 71 \\
155 / 87 \\
162 / 75(21 / 9) \\
\text { NS }\end{array}$ & $\begin{array}{l}57 \\
78 \\
81 \\
67 \\
48 \\
80 \\
53 \\
66(14) \\
\quad p\end{array}$ & $\begin{array}{l}39 \\
56 \\
31 \\
28 \\
41 \\
58 \\
37 \\
41(12) \\
0.005\end{array}$ & $\begin{array}{l}2 \cdot 1 \\
3 \cdot 2 \\
2 \cdot 7 \\
2 \cdot 1 \\
1 \cdot 9 \\
2 \cdot 2 \\
2 \cdot 8 \\
2 \cdot 4(0 \cdot 5)\end{array}$ & $\begin{array}{l}2 \cdot 5 \\
2 \cdot 6 \\
2 \cdot 7 \\
2 \cdot 6 \\
2 \cdot 1 \\
2 \cdot 0 \\
2 \cdot 8 \\
2 \cdot 5(0 \cdot 3) \\
\text { NS }\end{array}$ & $\begin{array}{l}179 \\
234 \\
134 \\
136 \\
152 \\
136 \\
231 \\
172(44) \\
\quad p<\end{array}$ & $\begin{array}{l}245 \\
270 \\
197 \\
166 \\
163 \\
120 \\
259 \\
202(57) \\
0.05\end{array}$ & $\begin{array}{l}0.5 \\
0.6 \\
0.3 \\
0.4 \\
0.5 \\
0.3 \\
0.7 \\
0.47(0.15 \\
\quad \text { p }<\end{array}$ & 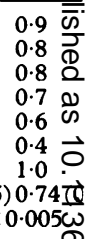 \\
\hline
\end{tabular}

AA, aortic area $\left(\mathrm{cm}^{2}\right) ; \mathrm{AF}$, systolic aortic flow (ml/s); CI, cardiac index $\left(1 / \mathrm{min} / \mathrm{m}^{2}\right) ; \mathrm{LV}$, left ventricular peak systolic and end diastolic pressures $\mathrm{Hg}$; $\mathrm{MSG}$, mean systolic aortic gradient $(\mathrm{mm} \mathrm{Hg})$.

and transvalvar gradient had been measured, an exchange 0.038 inch straight guide wire, with its soft tip manually fashioned to a big J shape, was positioned in the left ventricle. With this guide wire left in place, the Judkins catheter was removed and a dilatation catheter was advanced across the aortic valve, after careful removal of the air from the balloon.

The balloon was inflated by hand injection with a mixture of contrast medium and saline (30/70) at pressures of $400-600 \mathrm{kPa}$ (4-6 atmospheres). Initially a balloon of $13-15 \mathrm{~mm}$ was used, and after the balloon was in a stable position across the aortic valve (Fig 1) a series of 10-15 seconds inflations were performed. Waisting of the inflated balloon was not usually seen. At the end of each series of dilatations with the same balloon, left ventricular pressure, aortic pressure, cardiac output, systolic aortic flow, and aortic valve area were reassessed. Balloons of

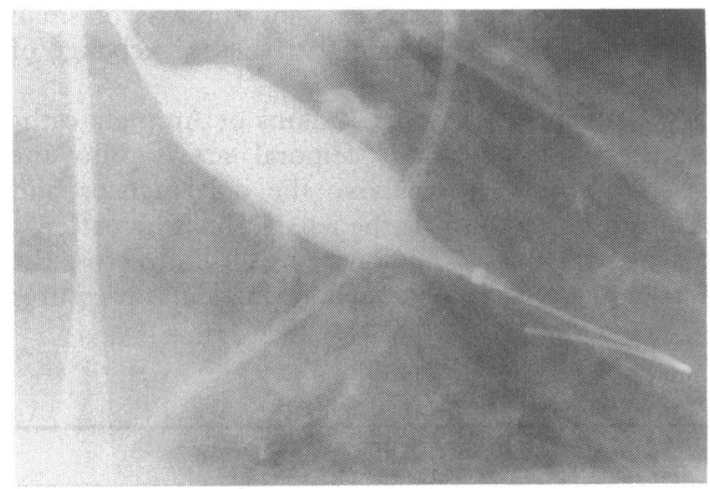

Fig 1 Aortogram of balloon dilatation of a stenotic aortic valve. The balloon, positioned across the heavily calcified aortic valve, was manually inflated to a diameter of $20 \mathrm{~mm}$. The guide wire was left in place in order to stabilise the position of the balloon. In this patient indentations of the balloon were not seen at any time during the procedure. $A$ Swan-Ganz thermodilution catheter and a pigtail catheter were placed in the pulmonary artery and the descending aorta respectively. increasing diameter were used to reduce the mean transstenotic gradient to $<40 \mathrm{~mm} \mathrm{Hg}$ and to increase the aortic valve area to $>1.0 \mathrm{~cm}^{2}$. If these end points could not be obtained with a $20 \mathrm{~mm}$ balloon additional dilatations were performed with a $3 \times 12 \mathrm{~mm}(25 \mathrm{~mm})$ trefoil balloon (Schneider Medintag Zürich). Figure 2 shows the reduction in mean systolic gradient obtained with the conventional $13-20 \mathrm{~mm}$ balloons and the additional benefit achieved with the larger balloon. The mean number of balloons used per patient was 3.8 (range 3-6) and the mean number of dilatations per patient was 8.6 (range 6-14). Balloons of two different lengths were used $(40$ and $80 \mathrm{~mm}$ ). One trefoil balloon could not be inserted into the femoral artery and five balloons ruptured during the inflations.

At the end of the procedure the presence of aortic regurgitation was assessed by supravalvar aortography.

STATISTICAL ANALYSIS

Student's $t$ test for paired data was used whenever appropriate.

\section{Results}

\section{HAEMODYNAMIC DATA}

Table 2 shows the haemodynamic variables measured soon after the last percutaneous aortic balloon dilatation and the same data before dilatation. Statistically significant decreases in peak systolic and end diastolic ventricular pressure, in mean systolic and peak systolic gradient, aortic flow, and valve area were achieved; there was also a slight but not statistically significant increase in cardiac index. Figure 3 shows the aortic valve areas before and after dilatation; all patients had an increase in aortic valve $\mathscr{D}$ area at the end of the procedure. None the less in three patients the aortic valve area was still $\leqslant 0.7 \mathrm{~cm}^{2}$ after dilatation. Similar improvements were shown when the mean systolic gradient was evaluated (Fig 4): in all but three of the patients a decrease $>20 \mathrm{~mm}$ 


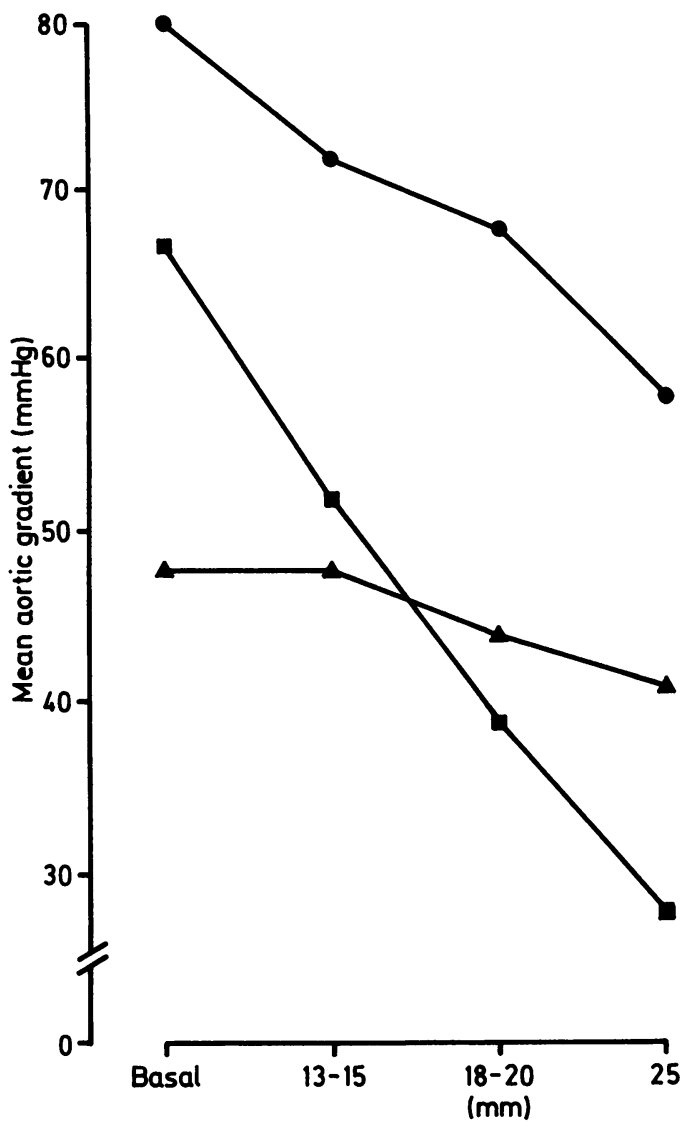

Fig 2 Mean systolic gradient after successive dilatations with balloons of increasing diameter $(13-15,18-20$, and 25 $\mathrm{mm}$ ) in the three patients who had dilatation with a trefoil balloon showing the additional improvement in gradient achieved with larger balloons.

$\mathrm{Hg}$ was achieved; in these three mean systolic gradients $>40 \mathrm{~mm} \mathrm{Hg}$ were present after dilatation.

\section{AORTIC INSUFFICIENCY}

Supravalvar aortography immediately after dilatation showed an increase in aortic regurgitation in four patients, but no patient had more than moderate regurgitation $(2+/ 4+)$ at the end of the procedure.

\section{COMPLICATIONS}

Repeat inflations of the balloon, positioned across the aortic valve were usually well tolerated: in most patients there was a moderate decrease in the aortic pressure, which was continuously monitored during the procedure, but the peak systolic pressure fell to $40 \mathrm{~mm} \mathrm{Hg}$ in only one (case 8); this was associated with a symptom of dizziness. Patient 5 complained of mild chest pain during and immediately after most of the inflations, with no further ST-segment change. Patient 2 needed surgical repair of a right femoral pseudoaneurysm two months after percutaneous aortic balloon dilatation; in this patient more catheters (six) were used because two balloons ruptured during inflation. In patient 5, a large haematoma developed at the site of balloon insertion in the right groin. Patient 6 experienced considerable hypotension, ST segment elevation, and loss of consciousness immediately after a $25 \mathrm{~mm}$ balloon had ruptured during inflation; she recovered completely within three minutes. Despite careful venting of the balloon before insertion, an air embolus was suspected.

A complete left hemianopia was present in patient 3 at the end of the procedure; computerised axial tomography suggested a small infarction in the area supplied by the right posterior cerebral artery. Minor residual defects of the field of vision were still present at discharge.

\section{SHORT TERM FOLLOW UP}

We obtained data on clinical follow up (35 days to 8 months, mean 4.5 months). In five patients the clinical improvement (at least by one functional New York Heart Association class) persisted. The other two patients (cases 1 and 6) subsequently underwent

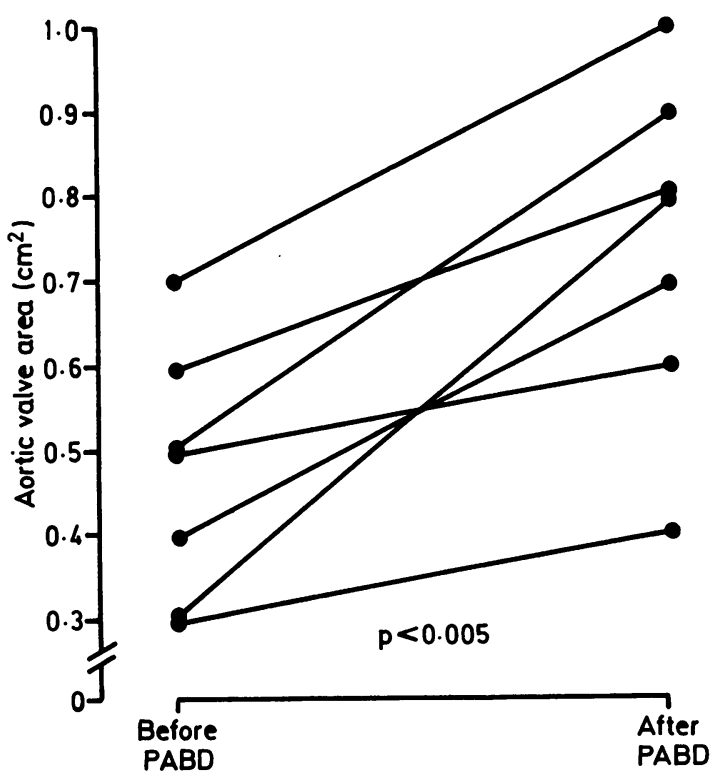

Fig 3 Aortic valve area before and after dilatation in 7 elderly patients. $P A B D$, percutaneous aortic balloon dilatation. 


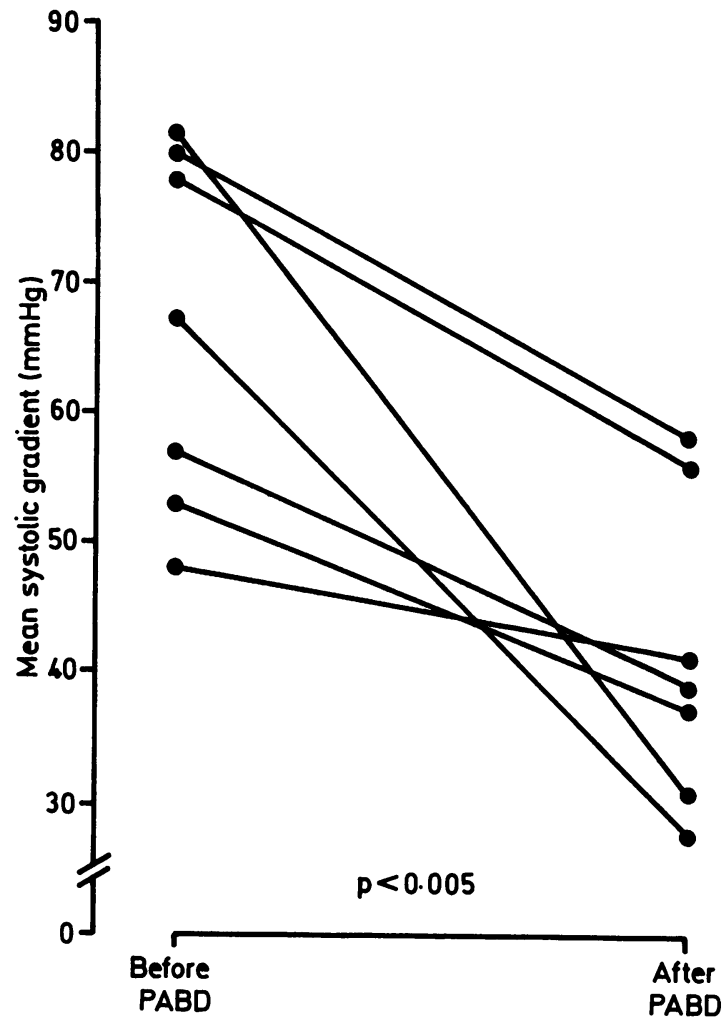

Fig 4 Mean systolic aortic gradient before and after aortic dilatation in seven elderly patients. $P A B D$, percutaneous aortic balloon dilatation.

uncomplicated aortic valve replacement. After a successful percutaneous aortic balloon dilatation (aortic valve area increased from 0.5 to $0.9 \mathrm{~cm}^{2}$ ) patient 1 experienced considerable functional improvement with disappearance of angina and syncopal attacks for three months, after which there was recurrence of angina and worsening of effort tolerance. EchoDoppler cardiography showed that the peak aortic flow velocity, which had been reduced from $5 \mathrm{~m} / \mathrm{s}$ to $2.5 \mathrm{~m} / \mathrm{s}$, had increased again to $4.5 \mathrm{~m} / \mathrm{s}$. After a syncopal attack, an aortic valve replacement was performed. The native bicuspid valve was diffusely calcified without commissural fusion; there was no tearing of the leaflet edges nor other macroscopic findings that might be related to the previous dilatation. A histological evaluation showed gross calcific deposits with bony degeneration, associated with fragmented areas of calcification, surrounded by connective tissue consisting of young fibroblasts with infiltrating lymphocytes and plasma cells (fig 5 ). Patient 6 was operated on 40 days after percutaneous aortic balloon dilatation because of the persistence of dyspnoea on minimal effort and at rest: the valve was tricuspid, with partial commissural fusion, diffuse thickening, and isolated nodular calcifications; no macroscopic damage or modifications related to percutaneous aortic balloon dilatation were found. Histological examination showed small areas of combined calcific fragments and fibrous tissue with some plasma cells.

\section{Discussion}

An increase in life expectancy and an improvement in the quality of life should not be denied to elderly patients with symptomatic aortic valve stenosis: at present aortic valve replacement is the most effective treatment but operative mortality ranges from 3\% to $18 \%,{ }^{8}$ and higher rates have been reported in patients who are older than $75^{9}$ or who have undergone emergency operation and are in poor general health. ${ }^{10}$ Moreover, coexisting cardiac or extracardiac disease may preclude operation.

Balloon dilatation of the aortic valve was introduced in 1983 for young patients with congenital aortic stenosis ${ }^{11}$ and only recently applied to cases of severe, calcified aortic valve stenosis in elderly patients. ${ }^{12}$

MECHANISM OF BALLOON DILATATION OF THE AORTIC VALVE

Degeneration of the fibrous stroma of the valves, lipid accumulation, and microscopically identifiable calcifications are common abnormalities in the elderly. ${ }^{13}$ In a few cases nodular calcific deposits on the aortic aspects of the cusps result in a critical reduction in the leaflet motility. A triradiate orifice, with lack or near lack of commissural fusion, is usually preserved. Among 111 necropsy specimens analysed by Pomerance, senile, degenerative (Mönckeberg) calcification of the aortic valve accounted for $61 \%$ of cases of aortic stenosis in patients aged between 75 and 85 years and for nearly all patients older than 85 years. ${ }^{14}$ The next most frequent finding in patients over 75 years of age and the commonest finding in younger patients, with a peak incidence occurring in the fifth and sixth decades, ${ }^{15}$ was degenerative calcification in congenitally bicuspid aortic valves: a transverse or slightly crescentic slit-like orifice, extending completely across the aortic lumen, was usually seen. Occasionally an inflammatory (rheumatic) pathogenesis is present in elderly patients ${ }^{16}$ and heavily calcified commissures are the most common finding in such patients.

In contrast with reports of dilatation in pulmonary and mitral valve stenosis, ${ }^{17}$ where separation of the fused commissures results in haemodynamic improvement, the pathogenesis of the aortic stenosis 


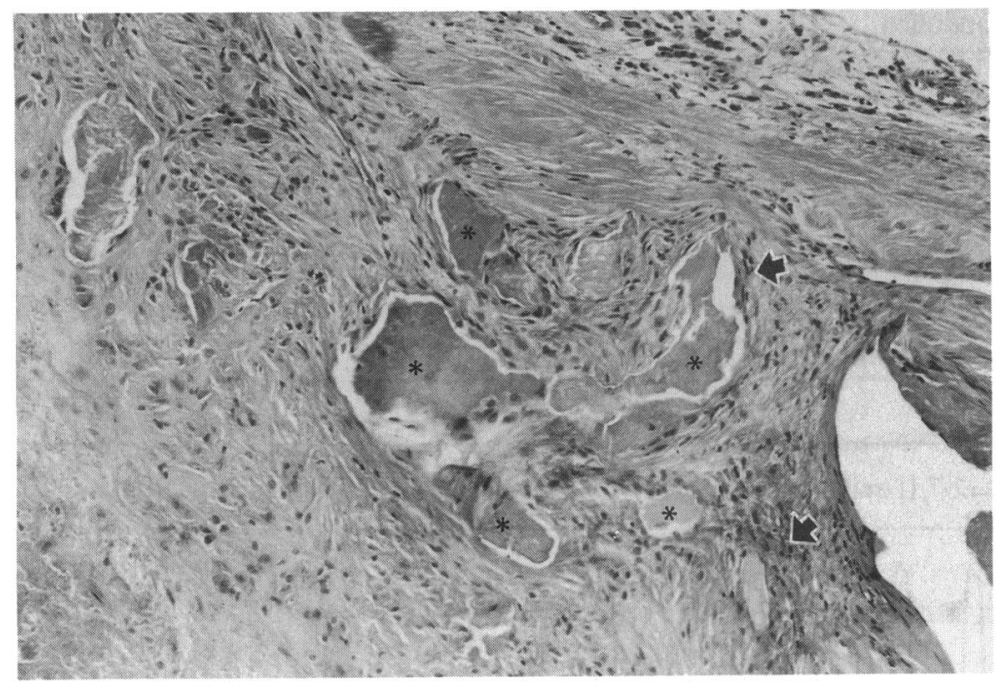

Fig 5 Photomicrograph of a restenosed bicuspid aortic valve replaced 5 months after aortic balloon dilatation (haematoxylin and eosin stain; original magnification $\times 100)$. Particles of calcium (*) were embedded in the valve tissue and were surrounded by scar tissue consisting of young fibroblasts and infiltrating lymphocytes and plasma cells (arrows).

in the elderly suggests that cusp separation does not have a major role. McKay et al recently performed postmortem or intraoperative percutaneous aortic balloon dilatation in 10 patients with an average age of 78 years: successful dilatation was related to a simple plastic deformation of the valve cusps in most patients, while fracture of heavy nodular calcifications and separation of fused commissures were less common findings. ${ }^{18}$ Similar findings have recently been reported by Reynolds et al. ${ }^{19}$ Vahanian et al, who performed postmortem dilatation in 22 bicuspid and tricuspid aortic valves, suggested that the mechanisms of percutaneous aortic balloon dilatation could be related to "an improvement in cusp motion due to calcium redistribution". 20

\section{SAFETY OF DILATATION}

Potential risks of percutaneous aortic balloon dilatation include damage to the peripheral vessels during insertion of multiple, stiff balloon catheters (ranging from 8 to $9 \mathrm{~F}$ ), occlusion of the aortic flow during balloon inflations, peripheral embolisation because calcific tissue is dislodged, and massive aortic insufficiency caused by gross tearing of the leaflets or to detachment of the cusps from the aortic ring.

Although extreme tortuosity and severe atherosclerosis of the peripheral vessels are often seen in patients of advanced age, correct positioning of the dilatation catheter via the femoral route was possible in seven of our eight patients. One late pseudoaneurysm of the common femoral artery required surgical repair.

Total occlusion of the aortic valve may induce a potentially dangerous rise in left ventricular pressure. To minimise this problem, an arteriovenous shunt was used during the first reported attempts of percutaneous aortic balloon dilatation in children. ${ }^{11}$ Our experience and the experience of others ${ }^{12}$ in elderly patients suggests that a residual flow is still present during balloon inflation; in six patients with calcified stenosis of the aortic valve no severe reduction of the arterial pressure was observed and only one patient experienced angina during the inflations.

Figure 6 summarises the haemodynamic findings during a three minute balloon inflation. ${ }^{21}$ This shows that there was no significant increase in intraventricular pressure and only a moderate decrease in arterial pressure and aortic flow. These observations and the frequent absence of evident waisting of the balloon during inflation suggest that the stiffness of the cusps and the non-circular configuration of the orifice prevent the complete adherence of the leaflets to the balloon and consequently avoids total valve occlusion, unlike the reported findings during pulmonary and aortic dilatations in the young where sudden orifice occlusion may produce abrupt haemodynamic changes.

Calcific stenosis of the aortic valve was regarded as a contraindication to percutaneous aortic balloon 

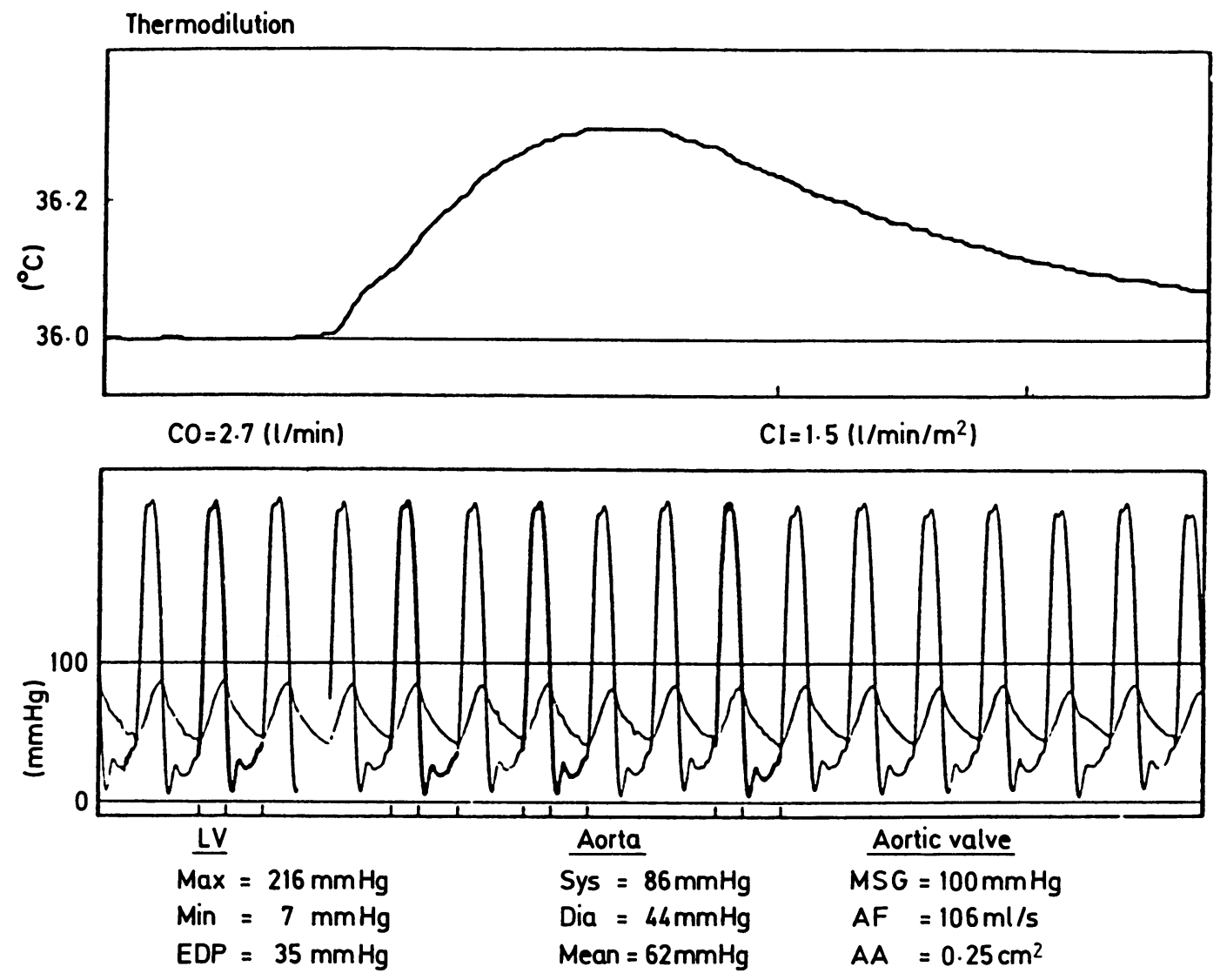

Fig 6 Cardiac output (thermodilution method) and left ventricular and aortic tracings during balloon inflation across the aortic valve; the balloon (diameter $20 \mathrm{~mm}$ ) was inflated for 3 minutes without subjective complaints. AA, aortic area; $A F$, systolic aortic flow; $C I$, cardiac index; $C O$, cardiac output; EDP, left ventricular end diastolic pressure; $L V$, left ventricle; $M S G$, mean systolic transaortic gradient.

dilatation when this technique was introduced. ${ }^{22}$ To date two embolic complications have been reported $^{2324}$ and the potential danger of peripheral embolisation cannot be ignored. In our series patient 3 had a small cerebral infarction, probably caused by a calcific embolus, with minor persistent functional damage.

None of our patients had a potentially dangerous increase in aortic insufficiency after percutaneous aortic balloon dilatation; nevertheless, at present percutaneous aortic balloon dilatation cannot be recommended in patients with greater than mild coexistent aortic insufficiency.

\section{IMMEDIATE RESULTS OF DILATATION}

McKay et al reported an increase in aortic valve area from 0.6 to $1.0 \mathrm{~cm}^{2}$ in 10 elderly patients ${ }^{25}$ while Jackson et al obtained a mean reduction greater than
$50 \%$ in peak systolic gradient in eight patients. ${ }^{26}$ The mean (SD) aortic area was increased from 0.45 $(0 \cdot 18)$ to $0.81(0.36) \mathrm{cm}^{2}$ in 158 patients collected by the French Registry. ${ }^{24}$ Comparable results were achieved in our patients (aortic valve area increased from 0.47 to $0.74 \mathrm{~cm}^{2}$ ) but a severely reduced absolute aortic valve area $\left(\leqslant 0.7 \mathrm{~cm}^{2}\right)$ persisted in three patients. We calculated the aortic valve area on the basis of mean gradient (planimetry of the area enclosed between simultaneously recorded left ventricular and aortic pressure tracing).

The lack of a considerable immediate improvement in some of our patients may be related to the anatomy of the aortic valve (percutaneous aortic balloon dilatation was partially unsuccessful in the patient with rheumatic aortic stenosis) or to inadequate balloon diameters (in three patients with unsuccessful haemodynamic improvements after 
repeated inflations of conventional $13-20 \mathrm{~mm}$ balloons we achieved better results using a $3 \times 12 \mathrm{~mm}$ $(25 \mathrm{~mm})$ trefoil balloon). The use of balloons $2-3$ $\mathrm{mm}$ smaller than the aortic annulus has been proposed in children to reduce the development of aortic regurgitation. ${ }^{27}$ The fear of gross tearing of the calcific leaflets or of their detachment from the aortic ring, with consequent massive aortic insufficiency, or of disruption of the aortic ring itself has resulted in even more caution in adult patients. In the reports of McKay et $a l,{ }^{25}$ Jackson $e t ~ a l^{26}$ and Cribier $e t ~ a l^{24}$ the largest balloon sizes used were 20,14, and $21 \mathrm{~mm}$ respectively. Postmortem and intraoperative data, however, suggest that larger balloons are needed for valves without commissural fusion or heavy nodular calcification. ${ }^{18}$

\section{EARLY FOLLOW UP}

Major functional improvements can be expected as a consequence of even relatively small increases in valve area, as has recently been reported in most patients after percutaneous aortic balloon dilatation. ${ }^{28}$ Five of our seven patients obtained persistent functional improvement, while two patients needed subsequent aortic valve replacement: in one of them a restenosis three months after percutaneous aortic balloon dilatation caused the late recurrence of symptoms and serial Doppler assessment showed increasing aortic flow velocity. In paediatric patients no increase in aortic stenosis was reported 3-9 months after percutaneous aortic balloon dilatation, ${ }^{29}$ but rates of increase in peak systolic gradient as high as 3-4 $\mathrm{mm} \mathrm{Hg}$ per month were described in adult patients with aortic stenosis. ${ }^{30}$ The lack of information on long term benefits after percutaneous aortic balloon dilatation necessitates a strict control programme.

Calcification surrounded by fibrous tissue can be found in aortic valves with stenosis of various aetiologies as well as in non-stenotic, sclerotic valves in the elderly. In our first patient, who was operated on five months after percutaneous aortic balloon dilatation because symptoms recurred, histology of the aortic valve suggested that a scarring process adjacent to the fragmented calcification was the mechanism of late restenosis.

Currently aortic dilatation provides effective palliative treatment in many patients with severe aortic stenosis, although it remains to be determined whether more definitive long term benefit can be expected. Further observations are needed to assess the efficacy and safety of the procedure (particularly when larger diameter balloons are used) as well as the progression of valve disease after dilatation.

$\mathrm{K} \mathrm{J} \mathrm{B} \mathrm{is} \mathrm{the} \mathrm{recipient} \mathrm{of} \mathrm{the} \mathrm{Joint} \mathrm{Fellowship} \mathrm{from}$ the British and Netherlands Heart Foundations.

\section{References}

1 Ross J Jr, Braunwald E. Aortic stenosis. Circulation 1968;38 V:61-7.

2 Frank S, Johnson A, Ross J Jr. Natural history of valvular aortic stenosis. Br Heart J 1973;35:41-6.

3 Jamieson WRE, Dooner J, Munro IA, et al. Cardiac valve replacement in the elderly: a review of 320 consecutive cases. Circulation 1981;64 II:177-83.

4 Arom KV, Nicholoff DM, Lindsay WG, Northrup WF, Kersten TE. Should valve replacement and related procedures be performed in elderly patients? Ann Thorac Surg 1984;38:466-72.

5 Storstein O, Efskind L. Aortic valve replacement in elderly patients. Acta Med Scand 1979;206:161-4.

6 Meester GT, Bernard N, Zeelenberg C, Brower RW, Hugenholtz PG. A computer system for real-time analysis of cardiac catheterization data. Cathet Cardiovasc Diagn 1975; 1:113-32.

7 Hochberg MS, Morrow AG, Michaelis LL, McIntosh CL, Redwood DR, Epstein SE. Aortic valve replacement in the elderly. Arch Surg 1977;112:1475-80.

8 Quinlan R, Cohn LH, Collins JJ Jr. Determinants of survival following cardiac operations in elderly patients. Chest 1975;68:498-500.

9 Cabrol C, Gandjbakhch I, Pavie A. La chirurgie de remplacement valvulaire. In: Acar J, ed. Cardiopathies valvulaires acquises. Paris: Flammarion Médicine-Sciences, 1985:513-46.

10 Glock Y, Pecoul R, Cerene A, Laguerre J, Puel F. Aortic valve replacement in elderly patients. J Cardiovasc Surg 1984;25:205-10.

11 Lababidi Z. Aortic balloon valvuloplasty. Am Heart J 1983;106:751-2.

12 Cribier A, Saoudi N, Berland J, Savin T, Rocha P, Letac B. Percutaneous transluminal valvuloplasty of acquired aortic stenosis in elderly patients: an alternative to valve replacement? Lancet 1986;i:63-7.

13 Pomerance A. Pathology of the myocardium and valves. In: Caird FI, Dall JLC, Kennedy RD, eds. Cardiology in old age. New York: Plenum Press, 1976:11-55.

14 Pomerance A. Pathogenesis of aortic stenosis and its relation to age. $\mathrm{Br}$ Heart $J$ 1972;34:569-74.

15 Fenoglio JJ Jr, McAllister HA Jr, DeCastro CM, Davia JE, Cheitlin MD. Congenital bicuspid aortic valve after age 20. Am J Cardiol 1977;39:164-9.

16 Roberts WC, Perloff JK, Costantino T. Severe valvular aortic stenosis in patients over 65 years of age. A clinicopathologic study. Am J Cardiol 1971;27:497-506.

17 Inoue $K$, Owaki $T$, Nakamura $T$, Kitamura $F$, Miyamoto N. Clinical application of transvenous mitral commissurotomy by a new balloon catheter. $J$ Thorac Cardiovasc Surg 1984;87:394-402.

18 McKay RG, Safian RD, Lock JE, et al. Balloon dilatation of calcific aortic stenosis in elderly patients: postmortem, intraoperative, and percutaneous valvuloplasty studies. Circulation 1986;74:119-25.

19 Reynolds DJM, Stone DL, Wells FC, Petch MC. How does aortic balloon valvuloplasty work? [Abstract.] Br Heart J 1987;57:70.

20 Vahanian A, Guérinon J, Slama M, Griveaux M, Acar J. Experimental balloon valvuloplasty of 
calcified aortic stenosis in the elderly [Abstract.] Circulation 1986;74 II:365.

21 Serruys PW, de Feyter PJ, van den Brand M. Percutaneous transluminal valvuloplasty of a narrowed aortic valve. A case report. Hart Bull 1986;6:171-6.

22 Walls JT, Lababidi Z, Curtis JJ, Silver D. Assessment of percutaneous balloon pulmonary and aortic valvuloplasty. J Thorac Cardiovasc Surg 1984;88:352-6.

23 Starkey IR, Cumberland DC, Oakley GDG. Balloon aortic valvuloplasty for severe calcific aortic stenosis: effective but not without hazards [Abstract.] $\mathrm{Br}$ Heart $J$ 1987;57:69.

24 Cribier A, Letac B, Lancelin B, et al. Percutaneous balloon valvuloplasty (PBV) for acquired aortic stenosis: preliminary immediate results of the French Registry [Abstract]. Circulation 1986;74 II:208.

25 McKay RG, Safian RD, Lock JE, et al. Percutaneous balloon valvuloplasty in elderly patients with calcific aortic stenosis [Abstract]. Circulation 1986;74 II:207.

26 Jackson G,Thomas S, Monaghan M, Forsyth A,
Jewitt D. Inoperable aortic stenosis in the elderly: benefit from percutaneous transluminal valvuloplasty. Br Med J 1987;294:83-6.

27 Choy M, Beekman RH, Crowley DC, Rocchini AP. Balloon dilatation in infants and children with valvular aortic stenosis [Abstract]. J Am Coll Cardiol 1986;7:117A.

28 Cribier A, Savin T, Saoudi N, Behar P, Rocha P, Letac B. Percutaneous balloon valvuloplasty (PBV) in adult aortic stenosis: an alternative to surgery for valve replacement [Abstract]. Circulation 1986; 74 II: 365.

29 Lababidi Z, Jiunn-Ren WU, Walls JT. Percutaneous balloon aortic valvuloplasty: results in 23 patients. Am J Cardiol 1984;53:149-97.

30 Cheitlin MD, Gertz EW, Brundage BH, Carlson CJ, Quash JA, Bode RS. Rate of progression of severity of valvular aortic stenosis in the adult. Am Heart $J$ 1979;98:689-700. 